\title{
Novel Two Degree of Freedom Model Matching Controller for Desired Tracking and Disturbance Rejection
}

\author{
FEBINA BEEVI P., SUNIL KUMAR TK, JEEVAMMA JACOB \\ National Institute of Technology-Calicut, \\ P O NITC, Calicut-673601, Kerala, India. \\ febinaeee@gmail.com, \\ tksunil@nitc.ac.in, \\ jeeva@nitc.ac.in.
}

\begin{abstract}
A control scheme is proposed in the present paper that introduces Two Degree of Freedom (2-DOF) controller to eliminate the effect of disturbances while tracking the desired trajectory, for Two-Input Two-output (TITO) systems, by implementing an original method that infuses three techniques such as the model order reduction, optimization and the approximate model matching techniques. From authors' knowledge, first time in literature, the objective of this kind of a proposed method is to accomplish a single low order 2-DOF controller, which can handle desired tracking and disturbance rejection simultaneously, using AGTM/AGMP matching method combined with optimization technique. The desired specifications for achieving the set-point tracking may be encompassed inside what resembles a transfer function matrix. This method is directed at ensuring that the closed loop system is stabilized by implementing a 2-DOF controller while also guaranteeing that it is capable of exhibiting the specified performance standards. This method is cost-effective, computationally simple, easy to implement and can be used for the design without any restriction in the structure/order of the model closed loop transfer function or 2-DOF controller. The efficacy of the proposed methodology is realized when it is performed on coupled tank process.
\end{abstract}

Keywords: AGTM/AGMP matching method; 2-DOF controller; model matching; model order reduction; TITO system.

\section{Introduction}

Modern control law design techniques based on LQG control and $\mathrm{H}_{\infty}$ optimization result in high-order controllers that are at least as complex as the model of the system to be controlled. The order of such controllers may be equal to that of the plant or may even exceed it. These high order controllers increase computational complexity. Optimal controllers often turn out to be fragile, i.e. they are very sensitive to coefficient perturbations and are more likely to go unstable under very small parameter changes. Moreover, such 'optimal' controllers often require feedback of all the states that makes state estimators mandatory. Thus, a need exists for a design method that provides a simple low order implementable controller, that too in a 2-DOF structure, which can simultaneously handle, desired tracking and disturbance rejection along with closed loop stability in MIMO plants, using only output feedback. The goal of the present paper is to design, for the first time, a 2-DOF controller for Two-Input Two-output (TITO) process, for set-point tracking and disturbance rejection, using Approximate Generalized Time Moments (AGTM)/Approximate Generalized Markov Parameters (AGMP) matching method and Genetic Algorithm. Although a significant attempt has been employed in the design of multivariable compensators, the designed its corresponding execution is a persistent problem for the control engineers as there are few or not practical approaches to deal with it. The methods $[6,9,5,26]$ works well for the SISO systems but cannot be applied on the MIMO systems. In the current paper, in conjunction with desired tracking, the importance of disturbance rejection and closed loop stability has been recognized. Most of the conventional controllers are in 1-DOF structure, where options for tuning are less $[3,4]$.

For simultaneously dealing with both the concerns that includes accomplishing the desired system response as is expected from the model and achieving the adequate disturbance rejection to nullify the effect of disturbance acting on the plant, it is important that the controller reaches a configuration of at least 2DOF [27,11]. However, the techniques implemented in altering the attributes of the 2DOF controllers have not been well positioned $[18,1,17]$. An improved performance can be achieved since the 2-DOF control structure isolates the disturbance from the reference. Moreover, this closed loop system implemented with a controller of 2-DOF specification exhibits the desired level of performance by accessing both the output and reference signals and comes under the same cost category of the controller that belongs to the 1-DOF specification. In addition to all these 
benefits, this proposed controller using the 2DOF specification always guarantees stability. In comparison to SISO complements, the processes that belong to MIMO controllers are more complicated to manage as there exist cross-coupling amidst the output and input variables. While designing the 2-DOF controller for MIMO systems presented in [2, 28] it employs SISO systems obtained as a result of decoupling. In contrast with this, the proposed method considers the MIMO transfer function, as it is, for the controller design. Another advantage of implementing this technique is that it is the most generalized one and does not belong to any specific criterion of systems.

The necessity of merging the controller design and the order reduction techniques has been specified in [8]. The implementation of the model matching technique for operating the controller design is quite old and dates back to several decades ago [12].The novel method in this paper combines both the concepts of model matching and order reduction in order to achieve an excellent 2-DOF controller design procedure, where all the data associated with the plant is maintained as such.

In this paper, the goal is to design, a low order implementable model matching 2-DOF controller for set-point tracking and disturbance rejection, while guaranteeing stability of the closed loop system, using model matching tool, based on AGTM/AGMP method, and optimization technique. The desired model, to be matched, is chosen as the closed loop system with specified performance. For the present work, this transfer function matrix for set-point tracking is specified as the closed loop transfer function matrix of the LQG controlled TITO system. This closed loop system that belongs to the 2-DOF specification is designed with an objective to have the performance same as that of the desired closed loop system. Genetic Algorithm (GA) is used to solve the optimization problem involved $[16,7,15,20]$. The major benefit of implementing this method is that it does not require two controllers to achieve disturbance rejection and set-point tracking simultaneously. Another advantage is that the controller structure and its order can be specified by the designer. In the current paper, to make it cost effective and to reduce the complexity of computation, the matrices $\mathrm{Q}(\mathrm{s})$, $\mathrm{H}(\mathrm{s})$ and $\mathrm{K}(\mathrm{s})$ of the 2-DOF controller are taken as diagonal. The method proposes a costeffective approach in comparison with the existing works, for achieving disturbance rejection and set-point tracking simultaneously. The method is simple to compute and can be implemented with ease. This system with the proposed 2-DOF controller is an output feedback system which is near-equivalent to an optimal state feedback one, if the desired performance is embodied in the model, specified as the LQG controlled system. In this sense, the controller proposed in this paper is suboptimal.

The remaining portion of this brief can be summarized as follows. Section 2 contributes to a general 2-DOF controller design problem formulation in a model matching framework. The anticipated technique for designing the controller that belongs to the specification of 2DOF is contained in Section 3. Likewise Section 4 contains the simulation results obtained by the implementation of the new method to a coupled-tank process. The paper is wrapped up with concluding remarks in Section 5.

\section{Problem Formulation}

The problem of designing a 2-DOF control system via model matching approach may be stated as follows: Given a process whose performance is unsatisfactory and a closed loop reference model having the desired performance, derive a 2-DOF controller such that performance of the augmented process matches that of the model. Important aspects of 2-DOF controller design and implementation, of concern, are the order and the subsequent hardware complexity. Usually, a high order plant is first reduced to a lower order one to facilitate the design of low order controllers. One may also first design a high order controller for the high order plant and then reduce its order, before implementation. Objective of the method developed in this paper is to directly design a low order implementable 2-DOF controller while ensuring closed loop stability and performance, approximating closely as that obtained by the original high order controller. Desired model for the proposed method is the closed loop system with LQG controller.

The 2-DOF controller design methodology developed in the present work has the following features:

- It is computationally simple.

- It is cost-effective.

- It ensures closed loop system stability 
- It yields practically implementable low-order controller.

- The method does not require plant reduction.

- Desired performance of the controlled system is specified at the outset.

Motivated by the above considerations, this is the first attempt, in authors' knowledge, to consider the problem of model matching 2DOF controller design for set-point tracking and disturbance rejection by AGTM/AGMP matching method.

\section{Proposed Method for 2-DOF Controller Design}

This section focuses on the concern of designing the 2-DOF model matching controller,which operates in output feedback form with the goal of guaranteeing desired tracking and disturbance rejection, while ensuring closed loop system stability. The closed loop system with the anticipated controller that belongs to the 2-DOF structure and plant $\mathrm{G}(\mathrm{s})$ is shown in Figure 1. The matrices $\mathrm{Q}(\mathrm{s}), \mathrm{H}(\mathrm{s})$ and $\mathrm{K}(\mathrm{s})$ in Figure 1 constitute the 2-DOF controller.

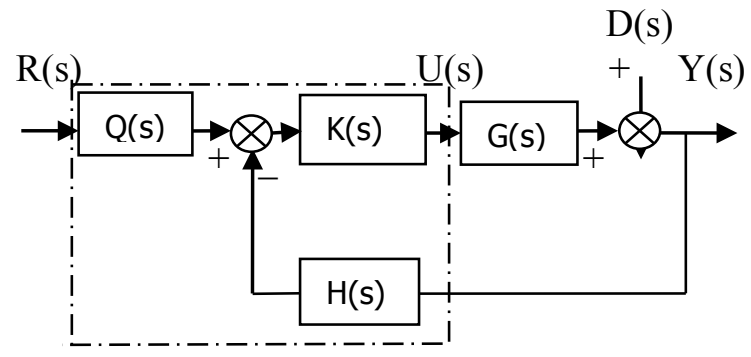

Figure 1. Closed loop system with 2-DOF controller

The two-input two-output open loop plant transfer function matrix $G(s)$ is supposed to have the form given below, where $\mathrm{G}_{11}(\mathrm{~s})$, $\mathrm{G}_{12}(\mathrm{~s}), \mathrm{G}_{21}(\mathrm{~s})$ and $\mathrm{G}_{22}(\mathrm{~s})$ are transfer functions.

$G(s)=\left[\begin{array}{ll}G_{11}(s) & G_{12}(s) \\ G_{21}(s) & G_{22}(s)\end{array}\right]$

The output $Y(\mathrm{~s})$ from Figure 1 is:

$\mathrm{Y}(\mathrm{s})=[\mathrm{I}+$

$\mathrm{G}(\mathrm{s}) \mathrm{K}(\mathrm{s}) \mathrm{H}(\mathrm{s})]^{-1} \mathrm{G}(\mathrm{s}) \mathrm{K}(\mathrm{s}) \mathrm{Q}(\mathrm{s}) \mathrm{R}(\mathrm{s})+$

$[\mathrm{I}+\mathrm{G}(\mathrm{s}) \mathrm{K}(\mathrm{s}) \mathrm{H}(\mathrm{s})]^{-1} \mathrm{D}(\mathrm{s})$

It can be written as:

$\mathrm{Y}(\mathrm{s})=\mathrm{C}_{\mathrm{L}_{1}}(\mathrm{~s}) \mathrm{R}(\mathrm{s})+\mathrm{C}_{\mathrm{L}_{2}}(\mathrm{~s}) \mathrm{D}(\mathrm{s})=\mathrm{Y}_{1}(\mathrm{~s})+$

$\mathrm{Y}_{2}(\mathrm{~s})$

where $\mathrm{C}_{\mathrm{L}_{1}}(\mathrm{~s})$ and $\mathrm{C}_{\mathrm{L}_{2}}(\mathrm{~s})$ are the closed loop transfer function matrices between the reference input $R(s)$ and the output $Y_{1}(s)$, and the closed loop transfer function matrix between the disturbance $\mathrm{D}(\mathrm{s})$ and the output $\mathrm{Y}_{2}(\mathrm{~s})$ respectively.

The closed loop transfer function matrices accomplished from Figure 1 are:

$\mathrm{C}_{\mathrm{L}_{1}}(\mathrm{~s})=[\mathrm{I}+\mathrm{G}(\mathrm{s}) \mathrm{K}(\mathrm{s}) \mathrm{H}(\mathrm{s})]^{-1} \mathrm{G}(\mathrm{s}) \mathrm{K}(\mathrm{s}) \mathrm{Q}(\mathrm{s})$

$\mathrm{C}_{\mathrm{L}_{2}}(\mathrm{~s})=[\mathrm{I}+\mathrm{G}(\mathrm{s}) \mathrm{K}(\mathrm{s}) \mathrm{H}(\mathrm{s})]^{-1}$

The following subsections, give the different phases of the proposed methodology.

\subsection{Model Selection:}

In this paper, $\mathrm{M}_{1}(\mathrm{~s})$ is the model closed loop transfer function matrix for achieving the desired tracking performance. For model matching, $\mathrm{M}_{1}(\mathrm{~s})$ should be matched with the closed loop transfer function matrix between the reference inputs $R(s)$ and the outputs $Y(s)$. $\mathrm{M}_{2}(\mathrm{~s})$ is chosen as the model closed loop transfer function matrix for the required disturbance rejection, and this has to be matched with the closed loop transfer function matrix between the disturbances $\mathrm{D}(\mathrm{s})$ and the outputs $\mathrm{Y}(\mathrm{s})$.

There are different ways in which the desired specification can be described. One way is, the desired specification can be encapsulated to take the form of the transfer function matrix, built from an array of time domain particularizations that includes rise time, settling time, peak over shoot, etc. The other methodology is in a state space form, in which the desired specification can be embodied in the weighting matrices of an optimal controller. The model having the specified performance for the present work is designed as the closed loop transfer function matrix of the LQG controlled TITO system. The specifications for the closed loop system are embodied in the weighting matrices as defined in the performance index required for the design of the LQG controller [24]. Resulting closed loop system can be taken as the desired model closed loop system $\mathrm{M}_{1}(\mathrm{~s})$ for set-point tracking.

$\mathrm{M}_{1}(\mathrm{~s})=\left[\begin{array}{ll}\mathrm{M}_{11}(\mathrm{~s}) & \mathrm{M}_{12}(\mathrm{~s}) \\ \mathrm{M}_{21}(\mathrm{~s}) & \mathrm{M}_{22}(\mathrm{~s})\end{array}\right]$

The model closed loop system $\mathrm{M}_{2}(\mathrm{~s})$ for disturbance rejection:

$\mathrm{M}_{2}(\mathrm{~s})=\left[\begin{array}{ll}\widetilde{\mathrm{M}}_{11}(\mathrm{~s}) & \widetilde{\mathrm{M}}_{12}(\mathrm{~s}) \\ \widetilde{\mathrm{M}}_{21}(\mathrm{~s}) & \widetilde{\mathrm{M}}_{22}(\mathrm{~s})\end{array}\right]$

For achieving tracking and disturbance rejection simultaneously, the model transfer function matrix for model matching is represented as: 
$\mathrm{M}(\mathrm{s})=\left[\begin{array}{ll}\mathrm{M}_{1}(\mathrm{~s}) & \mathrm{M}_{2}(\mathrm{~s})\end{array}\right]$

The closed loop transfer function matrix with 2-DOF controller is:

$\mathrm{C}_{\mathrm{L}}(\mathrm{s})=\left[\mathrm{C}_{\mathrm{L}_{1}}(\mathrm{~s}) \quad \mathrm{C}_{\mathrm{L}_{2}}(\mathrm{~s})\right]$

Define:

$\mathrm{Y}_{\mathrm{m}}(\mathrm{s})=\mathrm{Y}_{\mathrm{m}_{1}}(\mathrm{~s})+\mathrm{Y}_{\mathrm{m}_{2}}(\mathrm{~s})=\mathrm{M}_{1}(\mathrm{~s}) \mathrm{R}(\mathrm{s})+$

$\mathrm{M}_{2}(\mathrm{~s}) \mathrm{D}(\mathrm{s})$

$\mathrm{Y}_{\mathrm{m}}(\mathrm{s})$ is a combination of tracking response $\mathrm{Y}_{\mathrm{m}_{1}}(\mathrm{~s})$ and disturbance response $\mathrm{Y}_{\mathrm{m}_{2}}(\mathrm{~s})$. The final value $\mathrm{y}_{\mathrm{m}_{2}}(\infty) \triangleq \lim _{\mathrm{t} \rightarrow \infty} \mathrm{y}_{\mathrm{m}_{2}}(\mathrm{t})$ can be found out from its Laplace transform $\mathrm{Y}_{\mathrm{m}_{2}}(\mathrm{~s})$ by Final value theorem. If the function $y_{\mathrm{m}_{2}}(\mathrm{t})$ and its first derivative are Laplace transformable and $\mathrm{y}_{\mathrm{m}_{2}}(\mathrm{t})$ has the Laplace transform $\mathrm{Y}_{\mathrm{m}_{2}}(\mathrm{~s})$ and the $\lim _{\mathrm{s} \rightarrow 0} \mathrm{~s} \mathrm{Y}_{\mathrm{m}_{2}}(\mathrm{~s})$ exists, then:

$\mathrm{y}_{\mathrm{m}_{2}}(\infty)=\lim _{\mathrm{s} \rightarrow 0} \mathrm{~s} \mathrm{Y}_{\mathrm{m}_{2}}(\mathrm{~s})=\lim _{\mathrm{s} \rightarrow 0} \mathrm{~s} \mathrm{M}_{2}(\mathrm{~s}) \mathrm{D}(\mathrm{s})$

$\mathrm{Y}_{\mathrm{m}_{2}}(\mathrm{~s})$ is a converging signal. $\mathrm{Y}_{\mathrm{m}_{2}}(\mathrm{~s})$ should have denominator roots on the left half of splane, which indicates that $\mathrm{Y}_{\mathrm{m}_{2}}(\mathrm{~s})$ is a converging signal.

For an effective disturbance rejection, $\mathrm{M}_{2}(\mathrm{~s})$ should be selected such as given in Table 1, for different types of disturbance; where $\mathrm{M}_{\mathrm{N}}^{(\mathrm{i}, \mathrm{j})}(\mathrm{s})$ and $\mathrm{M}_{\mathrm{D}}^{(\mathrm{i}, \mathrm{j})}(\mathrm{s}), \mathrm{i}, \mathrm{j}=1,2$, are numerators and denominators of $\mathrm{M}_{2}(\mathrm{~s})$ respectively. The only condition is that $M_{D}^{(i, j)}(s)$ should be stable and should not have any roots at $\mathrm{s}=0$.

Table 1. Selection of $\mathrm{M}_{2}(\mathrm{~s})$

\begin{tabular}{|l|c|c|}
\hline $\begin{array}{l}\text { Serial } \\
\text { No. }\end{array}$ & $\begin{array}{c}\text { Type of } \\
\text { Disturbance }\end{array}$ & $\begin{array}{c}\text { Transfer Function } \\
\text { of } \mathrm{M}_{2}(\mathrm{~s})\end{array}$ \\
\hline 1 & Step & $\mathrm{s} \frac{\mathrm{M}_{\mathrm{N}}^{(\mathrm{i}, \mathrm{j})}(\mathrm{s})}{\mathrm{M}_{\mathrm{D}}^{(\mathrm{i}, \mathrm{j})}(\mathrm{s})}$ \\
\hline 2 & Ramp & $\mathrm{s}^{2} \frac{\mathrm{M}_{\mathrm{N}}^{(\mathrm{i}, \mathrm{j})}(\mathrm{s})}{\mathrm{M}_{\mathrm{D}}^{(\mathrm{i}, \mathrm{j})}(\mathrm{s})}$ \\
\hline 3 & Parabolic & $\mathrm{s}^{3} \frac{\mathrm{M}_{\mathrm{N}}^{(\mathrm{i}, \mathrm{j})}(\mathrm{s})}{\mathrm{M}_{\mathrm{D}}^{(\mathrm{i}, \mathrm{j})}(\mathrm{s})}$ \\
\hline 4 & Sinusoidal & $\mathrm{s}\left(\mathrm{s}^{2}+\omega^{2}\right) \frac{\mathrm{M}_{\mathrm{N}}^{(\mathrm{i}, \mathrm{j})}(\mathrm{s})}{\mathrm{M}_{\mathrm{D}}^{(\mathrm{i}, \mathrm{j})}(\mathrm{s})}$ \\
\hline
\end{tabular}

The matrices $\mathrm{Q}(\mathrm{s}), \mathrm{H}(\mathrm{s})$ and $\mathrm{K}(\mathrm{s})$ of the 2-DOF controller are chosen as diagonal, as shown in (11), (12) and (13):

$$
\mathrm{Q}(\mathrm{s})=\left[\begin{array}{cc}
\mathrm{q}_{1}(\mathrm{~s}) & 0 \\
0 & \mathrm{q}_{2}(\mathrm{~s})
\end{array}\right]
$$

$$
\begin{aligned}
& \mathrm{H}(\mathrm{s})=\left[\begin{array}{cc}
\mathrm{h}_{1}(\mathrm{~s}) & 0 \\
0 & \mathrm{~h}_{2}(\mathrm{~s})
\end{array}\right] \\
& \mathrm{K}(\mathrm{s})=\left[\begin{array}{cc}
\frac{1}{\mathrm{k}_{1}(\mathrm{~s})} & 0 \\
0 & \frac{1}{\mathrm{k}_{2}(\mathrm{~s})}
\end{array}\right]
\end{aligned}
$$

where $\mathrm{q}_{1}(\mathrm{~s}), \mathrm{q}_{2}(\mathrm{~s}), \mathrm{h}_{1}(\mathrm{~s}), \mathrm{h}_{2}(\mathrm{~s}), \mathrm{k}_{1}(\mathrm{~s})$ and $\mathrm{k}_{2}(\mathrm{~s})$ are polynomials of order $\mathrm{n}_{\mathrm{q} 1}, \mathrm{n}_{\mathrm{q} 2}, \mathrm{n}_{\mathrm{h} 1}, \mathrm{n}_{\mathrm{h} 2}, \mathrm{n}_{\mathrm{k} 1}$ and $n_{k 2}$ respectively, whose coefficients are to be determined. $\mathrm{k}_{1}(\mathrm{~s})$ and $\mathrm{k}_{2}(\mathrm{~s})$ are chosen as monic polynomials.

\subsection{AGTM/AGMP Matching Method:}

Padé approximation, originally introduced by Padé [10] is usually implemented across the model order reduction. The major drawbacks of this technique is that one cannot ensure the steadiness of the resulting depleted approximant in the situations involving the depletion order modelling, as well as it doesn't guarantee the stabilization of the closed loop system involving the controller as well as affecting it's design too.

A one-sided resolution to this concern as anticipated in Pal [19] by identifying a new collection of attributes called the Approximate Generalized Time Moments (AGTM) or Approximate Generalized Markov Parameters (AGMP) and that are used for controller design in $[21,22,23,25,14,13]$. In spite of trying to match the coefficients of expansion about $\mathrm{s}=0$ and $\mathrm{s}=\infty$, wherein one matches with $\mathrm{s}=\delta$ in which $\delta$ is selected to wrap up the complete frequency sequence of the interest.

\subsection{For Desired Tracking:}

In order to match $\mathrm{M}_{1}(\mathrm{~s})$ and $\mathrm{C}_{\mathrm{L}_{1}}(\mathrm{~s})$ for setpoint tracking:

$\left.\mathrm{M}_{1}(\mathrm{~s})\right|_{\mathrm{s}=\delta_{\mathrm{k}}}=\left.\mathrm{C}_{\mathrm{L}_{1}}(\mathrm{~s})\right|_{\mathrm{s}=\delta_{\mathrm{k}}}$

The expansion points $\delta_{\mathrm{k}}$ could be a positive or negative real number or a complex point that has been selected from any of the existing four quadrants of the s-plane. The minimum number of expansion points required may be made equal to the number of undetermined attributes of the controller to be determined.

$$
\begin{aligned}
& M_{1}(s)=[I+G(s) K(s) H(s)]^{-1} G(s) K(s) Q(s) \quad(15) \\
& {[I+G(s) K(s) H(s)] M_{1}(s)-G(s) K(s) Q(s)=O_{2 * 2}}
\end{aligned}
$$

Substituting $\mathrm{Q}(\mathrm{s}), \mathrm{H}(\mathrm{s})$ and $\mathrm{K}(\mathrm{s})$ as given in (11), (12) and (13) in (16), results in the following non-linear simultaneous equations 
in's'. For brevity of notation the argument, (s), has been dropped.

$M_{11} k_{1} k_{2}+G_{11} M_{11} h_{1} k_{2}+G_{12} M_{21} h_{2} k_{1}-G_{11} q_{1} k_{2}=0$ $M_{12} k_{1} k_{2}+G_{11} M_{12} h_{1} k_{2}+G_{12} M_{22} h_{2} k_{1}-G_{12} q_{2} k_{1}=0$ $M_{21} k_{1} k_{2}+G_{21} M_{11} h_{1} k_{2}+G_{22} M_{21} h_{2} k_{1}-G_{21} q_{1} k_{2}=0$ $\mathrm{M}_{22} \mathrm{k}_{1} \mathrm{k}_{2}+\mathrm{G}_{21} \mathrm{M}_{12} \mathrm{~h}_{1} \mathrm{k}_{2}+\mathrm{G}_{22} \mathrm{M}_{22} \mathrm{~h}_{2} \mathrm{k}_{1}-\mathrm{G}_{22} \mathrm{q}_{2} \mathrm{k}_{1}=0$

\subsubsection{Formation of Linear Homogenous Equations:}

In each term of (17), appear the product of $\mathrm{k}_{1}(\mathrm{~s})$ $\& \mathrm{k}_{2}(\mathrm{~s}), \mathrm{h}_{1}(\mathrm{~s}) \& \mathrm{k}_{2}(\mathrm{~s}), \mathrm{h}_{2}(\mathrm{~s}) \& \mathrm{k}_{1}(\mathrm{~s}), \mathrm{q}_{1}(\mathrm{~s}) \& \mathrm{k}_{2}(\mathrm{~s})$ and $\mathrm{q}_{2}(\mathrm{~s}) \& \mathrm{k}_{1}(\mathrm{~s})$. Since the 2-DOF controller polynomials $\mathrm{k}_{1}(\mathrm{~s}), \mathrm{k}_{2}(\mathrm{~s}), \mathrm{h}_{1}(\mathrm{~s}), \mathrm{h}_{2}(\mathrm{~s}), \mathrm{q}_{1}(\mathrm{~s})$ and $\mathrm{q}_{2}(\mathrm{~s})$ contains unknown coefficients, the product of $\mathrm{k}_{1}(\mathrm{~s}) \& \mathrm{k}_{2}(\mathrm{~s}), \mathrm{h}_{1}(\mathrm{~s}) \& \mathrm{k}_{2}(\mathrm{~s}), \mathrm{h}_{2}(\mathrm{~s}) \&$ $\mathrm{k}_{1}(\mathrm{~s}), \mathrm{q}_{1}(\mathrm{~s}) \& \mathrm{k}_{2}(\mathrm{~s})$ and $\mathrm{q}_{2}(\mathrm{~s}) \& \mathrm{k}_{1}(\mathrm{~s})$ will result in a non-linear terms of their unknown coefficients. Thus the polynomials introduced, $\mathrm{a}_{\mathrm{i}}(\mathrm{s}) ; \mathrm{i}=1,2,3,4,5$ in (18) through (22) are in the work so as to remove the complexity of the non-linear terms.

Thus defining,

$\mathrm{k}_{1}(\mathrm{~s}) \mathrm{k}_{2}(\mathrm{~s}) \cong \mathrm{a}_{1}(\mathrm{~s})$

$\mathrm{h}_{1}(\mathrm{~s}) \mathrm{k}_{2}(\mathrm{~s}) \cong \mathrm{a}_{2}(\mathrm{~s})$

$\mathrm{h}_{2}(\mathrm{~s}) \mathrm{k}_{1}(\mathrm{~s}) \cong \mathrm{a}_{3}(\mathrm{~s})$

$\mathrm{q}_{1}(\mathrm{~s}) \mathrm{k}_{2}(\mathrm{~s}) \cong \mathrm{a}_{4}(\mathrm{~s})$

$\mathrm{q}_{2}(\mathrm{~s}) \mathrm{k}_{1}(\mathrm{~s}) \cong \mathrm{a}_{5}(\mathrm{~s})$

Orders of the product polynomials, $\mathrm{a}_{\mathrm{i}}(\mathrm{s})$; $\mathrm{i}=1,2,3,4,5$, are obtained respectively as:

$\mathrm{n}_{1}=\mathrm{n}_{\mathrm{k}_{1}}+\mathrm{n}_{\mathrm{k}_{2}}$

$\mathrm{n}_{2}=\mathrm{n}_{\mathrm{h}_{1}}+\mathrm{n}_{\mathrm{k}_{2}}$

$\mathrm{n}_{3}=\mathrm{n}_{\mathrm{h}_{2}}+\mathrm{n}_{\mathrm{k}_{1}}$

$\mathrm{n}_{4}=\mathrm{n}_{\mathrm{q}_{1}}+\mathrm{n}_{\mathrm{k}_{2}}$

$\mathrm{n}_{5}=\mathrm{n}_{\mathrm{q}_{2}}+\mathrm{n}_{\mathrm{k}_{1}}$

After substituting (18) through (22) in (17), the non-linear equations are converted into a set of linear non-homogeneous equations of the form: $M_{11} a_{1}+G_{11} M_{11} a_{2}+G_{12} M_{21} a_{3}-G_{11} a_{4}=0$ $M_{12} a_{1}+G_{11} M_{12} a_{2}+G_{12} M_{22} a_{3}-G_{12} a_{5}=0$

$M_{21} a_{1}+G_{21} M_{11} a_{2}+G_{22} M_{21} a_{3}-G_{21} a_{4}=0$

$M_{22} a_{1}+G_{21} M_{12} a_{2}+G_{22} M_{22} a_{3}-G_{22} a_{5}=0$

Instead of finding the coefficients of the polynomials of $\mathrm{k}_{1}(\mathrm{~s}), \mathrm{k}_{2}(\mathrm{~s}), \mathrm{h}_{1}(\mathrm{~s}), \mathrm{h}_{2}(\mathrm{~s}), \mathrm{q}_{1}(\mathrm{~s})$ and $\mathrm{q}_{2}(\mathrm{~s})$, the proposed method finds the coefficients of the product polynomials $\mathrm{a}_{1}(\mathrm{~s})$, $\mathrm{a}_{2}(\mathrm{~s}), \mathrm{a}_{3}(\mathrm{~s}), \mathrm{a}_{4}(\mathrm{~s})$ and $\mathrm{a}_{5}(\mathrm{~s})$. Hence, the process for solving an array of non-linear equations for an optimum number of expansion points is reduced to solving an array of linearly nonhomogeneous equations for a similar number of expansion points.

The method itself assures internal stability of the controller, since the solution of parameters of 2-DOF controller is obtained from the solution of simultaneous linear equation in (24), which in turn is formulated on the base of expansion points by heuristic approach.

\subsubsection{Conversion to Matrix form:}

Since $\mathrm{k}_{1}(\mathrm{~s})$ and $\mathrm{k}_{2}(\mathrm{~s})$ are chosen as monic polynomials, $\mathrm{a}_{1}(\mathrm{~s})$ will also be a monic polynomial, as shown in Eq.(24):

$\mathrm{a}_{1}(\mathrm{~s})=\mathrm{s}^{\mathrm{n}_{1}}+\mathrm{X}_{1}^{(1)} \mathrm{s}^{\mathrm{n}_{1}-1}+\mathrm{X}_{1}^{(2)} \mathrm{s}^{\mathrm{n}_{1}-2}+\cdots+$

$\mathrm{X}_{1}^{\left(\mathrm{n}_{1}\right)} \mathrm{s}^{0}$

This can be written in matrix form as:

$\mathrm{a}_{1}(\mathrm{~s})=\mathrm{s}^{\mathrm{n}_{1}}+\mathrm{S}_{1} \mathrm{X}_{1}$

Where

$S_{1}=\left[\begin{array}{lllll}s^{n_{1}-1} & s^{n_{1}-2} & \ldots & s & s^{0}\end{array}\right]$

$\mathrm{X}_{1}=\left[\begin{array}{lllll}\mathrm{X}_{1}^{(1)} & \mathrm{X}_{1}^{(2)} & \ldots & \mathrm{X}_{1}^{\left(\mathrm{n}_{1}-1\right)} & \mathrm{X}_{1}^{\left(\mathrm{n}_{1}\right)}\end{array}\right]^{\mathrm{T}}$

Similarly $a_{2}(s), a_{3}(s), a_{4}(s)$ and $a_{5}(s)$ can be written as:

$\mathrm{a}_{\mathrm{i}}(\mathrm{s})=\mathrm{S}_{\mathrm{i}} \mathrm{X}_{\mathrm{i}} \quad \mathrm{i}=2,3,4,5$.

where

$\mathrm{S}_{\mathrm{i}}=\left[\begin{array}{lllll}\mathrm{s}^{\mathrm{n}_{\mathrm{i}}} & \mathrm{s}^{\mathrm{n}_{\mathrm{i}}-1} & \ldots & \mathrm{s} & \mathrm{s}^{0}\end{array}\right]$

$X_{i}=\left[\begin{array}{lllll}X_{i}^{(1)} & X_{i}^{(2)} & \ldots & X_{i}^{\left(n_{i}\right)} & X_{i}^{\left(n_{i}+1\right)}\end{array}\right]^{T}$

$X_{i}$ 's are coefficients needs to be formed. The entire number of undetermined coefficients is, $\mathrm{N}=\mathrm{n}_{1}+\mathrm{n}_{2}+1+\mathrm{n}_{3}+1+\mathrm{n}_{4}+1+\mathrm{n}_{5}+1$. Using (26) and (29), (24) can be rearranged into a matrix equation of the form,

$\left[\begin{array}{ccccc}M_{11} S_{1} & G_{11} M_{11} S_{2} & G_{12} M_{21} S_{3} & -G_{11} S_{4} & O_{5} \\ M_{12} S_{1} & G_{11} M_{12} S_{2} & G_{12} M_{22} S_{3} & O_{4} & -G_{12} S_{5} \\ M_{21} S_{1} & G_{21} M_{11} S_{2} & G_{22} M_{21} S_{3} & -G_{21} S_{4} & O_{5} \\ M_{22} S_{1} & G_{21} M_{12} S_{2} & G_{22} M_{22} S_{3} & O_{4} & -G_{22} S_{5}\end{array}\right]\left[\begin{array}{l}X_{1} \\ X_{2} \\ X_{3} \\ X_{4} \\ X_{5}\end{array}\right]=$

$-s^{n_{1}}\left[\begin{array}{l}M_{11} \\ M_{12} \\ M_{21} \\ M_{22}\end{array}\right]$

$\mathrm{O}_{\mathrm{k}}=$ null matrix of $\mathrm{n}_{\mathrm{k}}+1$ columns. Equation (32) can be expressed in more condensed matrix form of simultaneous equations as:

$\mathrm{D}_{1} \mathrm{X}=\mathrm{F}_{1}$

where $D_{1}$ and $F_{1}$ are functions of " $s$ " and $X$ is the matrix of unknown parameters to be determined.

\subsection{For Disturbance Rejection:}

To match $\mathrm{M}_{2}(\mathrm{~s})$ and $\mathrm{C}_{\mathrm{L}_{2}}(\mathrm{~s})$ for disturbance rejection:

$\left.\mathrm{M}_{2}(\mathrm{~s})\right|_{\mathrm{s}=\delta_{\mathrm{k}}}=\left.\mathrm{C}_{\mathrm{L}_{2}}(\mathrm{~s})\right|_{\mathrm{s}=\delta_{\mathrm{k}}}$

Equation (34) results in the following nonlinear simultaneous equations in's'. 
$\widetilde{\mathrm{M}}_{11} \mathrm{k}_{1} \mathrm{k}_{2}+\mathrm{G}_{11} \widetilde{\mathrm{M}}_{11} \mathrm{~h}_{1} \mathrm{k}_{2}+\mathrm{G}_{12} \widetilde{\mathrm{M}}_{21} \mathrm{~h}_{2} \mathrm{k}_{1}=0$

$\widetilde{\mathrm{M}}_{12} \mathrm{k}_{1} \mathrm{k}_{2}+\mathrm{G}_{11} \widetilde{\mathrm{M}}_{12} \mathrm{~h}_{1} \mathrm{k}_{2}+\mathrm{G}_{12} \widetilde{\mathrm{M}}_{22} \mathrm{~h}_{2} \mathrm{k}_{1}=0$

$\widetilde{\mathrm{M}}_{21} \mathrm{k}_{1} \mathrm{k}_{2}+\mathrm{G}_{21} \widetilde{\mathrm{M}}_{11} \mathrm{~h}_{1} \mathrm{k}_{2}+\mathrm{G}_{22} \widetilde{\mathrm{M}}_{21} \mathrm{~h}_{2} \mathrm{k}_{1}=0$

$\widetilde{\mathrm{M}}_{22} \mathrm{k}_{1} \mathrm{k}_{2}+\mathrm{G}_{21} \widetilde{\mathrm{M}}_{12} \mathrm{~h}_{1} \mathrm{k}_{2}+\mathrm{G}_{22} \widetilde{\mathrm{M}}_{22} \mathrm{~h}_{2} \mathrm{k}_{1}=0$

\subsubsection{Formation of Linear Homogenous Equations:}

In order to simplify the solution, the product of $\mathrm{k}_{1}(\mathrm{~s}) \& \mathrm{k}_{2}(\mathrm{~s}), \mathrm{h}_{1}(\mathrm{~s}) \& \mathrm{k}_{2}(\mathrm{~s}), \mathrm{h}_{2}(\mathrm{~s}) \& \mathrm{k}_{1}(\mathrm{~s}), \mathrm{q}_{1}(\mathrm{~s}) \&$ $\mathrm{k}_{2}(\mathrm{~s})$ and $\mathrm{q}_{2}(\mathrm{~s}) \& \mathrm{k}_{1}(\mathrm{~s})$ are set as single polynomials $a_{i}(s) ; i=1,2,3,4,5$ in (18) through (22).

$$
\begin{aligned}
& \widetilde{\mathrm{M}}_{11} \mathrm{a}_{1}+G_{11} \widetilde{\mathrm{M}}_{11} \mathrm{a}_{2}+\mathrm{G}_{12} \widetilde{\mathrm{M}}_{21} \mathrm{a}_{3}=0 \\
& \widetilde{\mathrm{M}}_{12} \mathrm{a}_{1}+G_{11} \widetilde{\mathrm{M}}_{12} \mathrm{a}_{2}+\mathrm{G}_{12} \widetilde{\mathrm{M}}_{22} \mathrm{a}_{3}=0 \\
& \widetilde{\mathrm{M}}_{21} \mathrm{a}_{1}+G_{21} \widetilde{\mathrm{M}}_{11} \mathrm{a}_{2}+\mathrm{G}_{22} \widetilde{\mathrm{M}}_{21} \mathrm{a}_{3}=0 \\
& \widetilde{\mathrm{M}}_{22} \mathrm{a}_{1}+\mathrm{G}_{21} \widetilde{\mathrm{M}}_{12} \mathrm{a}_{2}+\mathrm{G}_{22} \widetilde{\mathrm{M}}_{22} \mathrm{a}_{3}=0
\end{aligned}
$$

Now solving an array of non-linear equations is reduced to solving an array of linearly nonhomogeneous equations for a similar number of expansion points.

\subsubsection{Conversion to Matrix form:}

Since $\mathrm{k}_{1}(\mathrm{~s})$ and $\mathrm{k}_{2}(\mathrm{~s})$ are chosen as monic polynomial, $\mathrm{a}_{1}(\mathrm{~s})$ can be written in matrix form as in (26) and $\mathrm{a}_{\mathrm{i}}(\mathrm{s}), \mathrm{i}=2,3,4,5$, can be written as in (29) respectively. Rearrange (36) into a matrix equation of the form:

$$
\begin{aligned}
& {\left[\begin{array}{llllll}
\widetilde{\mathrm{M}}_{11} \mathrm{~S}_{1} & \mathrm{G}_{11} \widetilde{\mathrm{M}}_{11} \mathrm{~S}_{2} & \mathrm{G}_{12} \widetilde{\mathrm{M}}_{21} \mathrm{~S}_{3} & \mathrm{O}_{4} & \mathrm{O}_{5} \\
\widetilde{\mathrm{M}}_{12} \mathrm{~S}_{1} & \mathrm{G}_{11} \widetilde{\mathrm{M}}_{12} \mathrm{~S}_{2} & \mathrm{G}_{12} \widetilde{\mathrm{M}}_{22} \mathrm{~S}_{3} & \mathrm{O}_{4} & \mathrm{O}_{5} \\
\widetilde{\mathrm{M}}_{21} \mathrm{~S}_{1} & \mathrm{G}_{21} \widetilde{\mathrm{M}}_{11} \mathrm{~S}_{2} & \mathrm{G}_{22} \widetilde{\mathrm{M}}_{21} \mathrm{~S}_{3} & \mathrm{O}_{4} & \mathrm{O}_{5} \\
\widetilde{\mathrm{M}}_{22} \mathrm{~S}_{1} & \mathrm{G}_{21} \widetilde{\mathrm{M}}_{12} \mathrm{~S}_{2} & \mathrm{G}_{22} \widetilde{\mathrm{M}}_{22} \mathrm{~S}_{3} & \mathrm{O}_{4} & \mathrm{O}_{5}
\end{array}\right]\left[\begin{array}{l}
\mathrm{X}_{1} \\
\mathrm{X}_{2} \\
\mathrm{X}_{3} \\
\mathrm{X}_{4} \\
\mathrm{X}_{5}
\end{array}\right]=} \\
& -\mathrm{s}^{\mathrm{n}_{1}}\left[\begin{array}{l}
\mathrm{M}_{11} \\
\mathrm{M}_{12} \\
\mathrm{M}_{21} \\
\mathrm{M}_{22}
\end{array}\right]
\end{aligned}
$$

Whenever it requires disturbance rejecting 2DOF controller design alone, then the designer need to find out only the first three polynomials $a_{i}(s)$; $i=1,2,3$ corresponding to $X_{1}, X_{2}$ and $X_{3}$. Then the null matrices $\mathrm{O}_{4}$ and $\mathrm{O}_{5}$ need not be used.

Equation (37) can be expressed in more condensed matrix form of simultaneous equations as:

$$
\mathrm{D}_{2} \mathrm{X}=\mathrm{F}_{2}
$$

\subsection{Desired Tracking and Disturbance rejection}

The overall set of linear non-homogeneous equations is formulated by combining (33) and (38) to achieve tracking and output disturbance rejection simultaneously. This is given by:

$\mathrm{DX}=\mathrm{F}$

$\mathrm{D}=\left[\begin{array}{l}\mathrm{D}_{1} \\ \mathrm{D}_{2}\end{array}\right] \quad \mathrm{X}=\left[\begin{array}{l}\mathrm{X}_{\mathrm{q}} \\ \mathrm{X}_{\mathrm{h}} \\ \mathrm{X}_{\mathrm{k}}\end{array}\right] \quad \mathrm{F}=\left[\begin{array}{l}\mathrm{F}_{1} \\ \mathrm{~F}_{2}\end{array}\right]$ where $\mathrm{D}$ and $\mathrm{F}$ are functions of ' $\mathrm{s}$ ' and $\mathrm{X}$ is the matrix of unknown parameters to be determined.

\subsection{Evaluation about the Expansion points:}

Now evaluate $\mathrm{D}$ and $\mathrm{F}$ at the expansion points $\delta_{\mathrm{k}}$, such that:

$\left.\mathrm{DX}\right|_{\mathrm{s}=\delta_{\mathrm{k}}}=\left.\mathrm{F}\right|_{\mathrm{s}=\delta_{\mathrm{k}}}$

Let

$\mathrm{P}=\left.\mathrm{D}\right|_{\mathrm{s}=\delta_{\mathrm{k}}}$ and $\mathrm{R}=\left.\mathrm{F}\right|_{\mathrm{s}=\delta_{\mathrm{k}}}$

where $\mathrm{k}=1,2, \ldots \mathrm{n}$. Then

$\mathrm{PX}=\mathrm{R}$

where $\mathrm{P}$ and $\mathrm{R}$ are,

$\mathrm{P}=\left[\begin{array}{c}\mathrm{D}_{1} \\ \mathrm{D}_{2} \\ \vdots \\ \mathrm{D}_{\mathrm{n}}\end{array}\right] \quad \mathrm{R}=\left[\begin{array}{c}\mathrm{F}_{1} \\ \mathrm{~F}_{2} \\ \vdots \\ \mathrm{F}_{\mathrm{n}}\end{array}\right]$

Solution of (43) gives the unknown coefficients of the product polynomials $\mathrm{a}_{\mathrm{i}}(\mathrm{s}) ; \mathrm{i}=1,2,3,4,5$.

\subsection{Closed Loop Transfer Function Matrices:}

The closed loop transfer function matrices, $\mathrm{C}_{\mathrm{L}_{1}}(\mathrm{~s})$ and $\mathrm{C}_{\mathrm{L}_{2}}(\mathrm{~s})$ can be expressed as a function of product polynomials $\mathrm{a}_{\mathrm{i}}(\mathrm{s})$; $\mathrm{i}=1,2,3,4,5$ as:

$\mathrm{C}_{\mathrm{L}_{1}}(\mathrm{~s})=\frac{1}{\mathrm{~d}(\mathrm{~s})} \mathrm{N}_{1}(\mathrm{~s})$

where $\mathrm{d}(\mathrm{s})$ is common for $\mathrm{C}_{\mathrm{L}_{1}}(\mathrm{~s})$ and $\mathrm{C}_{\mathrm{L}_{2}}(\mathrm{~s})$.

$\mathrm{d}(\mathrm{s})=\left(\mathrm{a}_{1}\right)^{2}+\mathrm{a}_{1}\left(\mathrm{G}_{11} \mathrm{a}_{2}+\mathrm{G}_{22} \mathrm{a}_{3}\right)+$

$\left(\mathrm{G}_{11} \mathrm{G}_{22}-\mathrm{G}_{21} \mathrm{G}_{12}\right) \mathrm{a}_{2} \mathrm{a}_{3}$

and

$=\left[\begin{array}{cc}a_{4} G_{11}+\frac{a_{1} a_{5}}{a_{1}}\left(G_{11} G_{22}-G_{12} G_{21}\right) & a_{5} G_{12} \\ a_{4} G_{21} & a_{5} G_{22}+\frac{a_{5} a_{2}}{a_{1}}\left(G_{12} G_{22}-G_{12} G_{21}\right)\end{array}\right]$

Then $\mathrm{C}_{\mathrm{L}_{2}}(\mathrm{~s})$ can be expressed as:

$\mathrm{C}_{\mathrm{L}_{2}}(\mathrm{~s})=\frac{1}{\mathrm{~d}(\mathrm{~s})} \mathrm{N}_{2}(\mathrm{~s})$

Where

$N_{2}(s)=\left[\begin{array}{cc}\left(a_{1}\right)^{2}+G_{22} a_{3} a_{1} & -G_{12} a_{3} a_{1} \\ -G_{21} a_{2} a_{1} & \left(a_{1}\right)^{2}+G_{11} a_{2} a_{1}\end{array}\right]$

Hence without finding the 2-DOF controller polynomials, $\mathrm{q}_{1}(\mathrm{~s}), \mathrm{q}_{2}(\mathrm{~s}), \mathrm{h}_{1}(\mathrm{~s}), \mathrm{h}_{2}(\mathrm{~s}), \mathrm{k}_{1}(\mathrm{~s})$ and $\mathrm{k}_{2}$ (s), one can directly find out the closed loop transfer function matrices using the product polynomials $\mathrm{a}_{\mathrm{i}}(\mathrm{s}) ; \mathrm{i}=1,2,3,4,5$. 


\subsection{Two-Degree of Freedom Controller polynomials:}

The 2-DOF controller polynomials $\mathrm{q}_{1}(\mathrm{~s}), \mathrm{q}_{2}(\mathrm{~s})$, $\mathrm{h}_{1}(\mathrm{~s}), \mathrm{h}_{2}(\mathrm{~s}), \mathrm{k}_{1}(\mathrm{~s})$ and $\mathrm{k}_{2}(\mathrm{~s})$ can be found out from polynomials $\mathrm{a}_{\mathrm{i}}(\mathrm{s})$; $\mathrm{i}=1,2,3,4,5$, given in (18) through (22). The solution of these equations yields the parameters of the decentralized 2-DOF controller in the form of the coefficients of the polynomials $\mathrm{q}_{1}(\mathrm{~s}), \mathrm{q}_{2}(\mathrm{~s})$, $\mathrm{h}_{1}(\mathrm{~s}), \mathrm{h}_{2}(\mathrm{~s}), \mathrm{k}_{1}(\mathrm{~s})$ and $\mathrm{k}_{2}(\mathrm{~s})$. The present work suggests two approaches for this, namely, least square approach and hardware flexible approach.

\subsubsection{Least square approach:}

First approach is formulation of the simultaneous equations, keeping $\mathrm{k}_{1}(\mathrm{~s})$ and $\mathrm{k}_{2}(\mathrm{~s})$ as monic polynomials, yields least square solution of $\mathrm{q}_{1}(\mathrm{~s}), \mathrm{q}_{2}(\mathrm{~s}), \mathrm{h}_{1}(\mathrm{~s}), \mathrm{h}_{2}(\mathrm{~s}), \mathrm{k}_{1}(\mathrm{~s})$ and $\mathrm{k}_{2}(\mathrm{~s})$. In hardware flexible solution, select any two polynomials among $\mathrm{q}_{1}(\mathrm{~s}), \mathrm{q}_{2}(\mathrm{~s}), \mathrm{h}_{1}(\mathrm{~s}), \mathrm{h}_{2}(\mathrm{~s})$, $\mathrm{k}_{1}(\mathrm{~s})$ and $\mathrm{k}_{2}(\mathrm{~s})$, according to the availability of components and remaining polynomials can be found from (18) through (22), thereby giving flexibility in implementation.

From (18) and (19):

$\frac{\mathrm{a}_{1}(\mathrm{~s})}{\mathrm{a}_{2}(\mathrm{~s})}=\frac{\mathrm{k}_{1}(\mathrm{~s})}{\mathrm{h}_{1}(\mathrm{~s})}$

On cross multiplication:

$\mathrm{a}_{2}(\mathrm{~s}) \mathrm{k}_{1}(\mathrm{~s})=\mathrm{a}_{1}(\mathrm{~s}) \mathrm{h}_{1}(\mathrm{~s})$

From (18) and (20):

$\frac{\mathrm{a}_{3}(\mathrm{~s})}{\mathrm{a}_{1}(\mathrm{~s})}=\frac{\mathrm{h}_{2}(\mathrm{~s})}{\mathrm{k}_{2}(\mathrm{~s})}$

By cross multiplication of (52):

$\mathrm{a}_{3}(\mathrm{~s}) \mathrm{k}_{2}(\mathrm{~s})=\mathrm{a}_{1}(\mathrm{~s}) \mathrm{h}_{2}(\mathrm{~s})$

For finding out the unknown coefficients of the polynomials $\mathrm{h}_{1}(\mathrm{~s})$ and $\mathrm{k}_{1}(\mathrm{~s})$, equate the coefficients of equal powers of (51). To solve for the unknown coefficients of the polynomials $\mathrm{h}_{2}(\mathrm{~s})$ and $\mathrm{k}_{2}(\mathrm{~s})$, equate the coefficients of equal powers of (53). Knowing $\mathrm{k}_{1}(\mathrm{~s})$ and $\mathrm{k}_{2}(\mathrm{~s}), \mathrm{q}_{1}(\mathrm{~s})$ and $\mathrm{q}_{2}(\mathrm{~s})$ can be obtained from (21) and (22). This procedure results in least square solution of the 2-DOF controller polynomials $\mathrm{q}_{1}(\mathrm{~s}), \mathrm{q}_{2}(\mathrm{~s}), \mathrm{h}_{1}(\mathrm{~s}), \mathrm{h}_{2}(\mathrm{~s}), \mathrm{k}_{1}(\mathrm{~s}), \mathrm{k}_{2}(\mathrm{~s})$.

\subsubsection{Hardware flexible approach:}

There may be a chance of components not available for implementing the 2-DOF controller polynomials $\mathrm{q}_{1}(\mathrm{~s}), \mathrm{q}_{2}(\mathrm{~s}), \mathrm{h}_{1}(\mathrm{~s}), \mathrm{h}_{2}(\mathrm{~s})$, $\mathrm{k}_{1}(\mathrm{~s})$ and $\mathrm{k}_{2}(\mathrm{~s})$, obtained by least square approach given in section 3.8.1. Hence one can go for a solution by randomly selecting any two polynomials among $\mathrm{q}_{1}(\mathrm{~s}), \mathrm{q}_{2}(\mathrm{~s}), \mathrm{h}_{1}(\mathrm{~s}), \mathrm{h}_{2}(\mathrm{~s})$, $\mathrm{k}_{1}(\mathrm{~s})$ and $\mathrm{k}_{2}(\mathrm{~s})$, according to the availability of components and remaining polynomials can be found from (18) through (22). This way of selection ensures the internal stability of 2DOF controller, by appropriately choosing any two denominator polynomials, and remaining polynomials can be determined from (18) through (22). This hardware flexible solution may give hardware flexibility in implementation of 2-DOF controller.

\subsection{Optimal Expansion points and Closed loop system Stability:}

In the current scenario that involves the controller design, the selection of the extension points is determined depending on the stabilization and execution of the closed loop system. It is imperative to design the controller in such a way that the closed loop system responds in a satisfying manner where in it meets the expected specifications also, ensuring the stability of the closed loop structure alongside. In the current scenario, the goals of selecting optimum expansion points is assumed to be one of the constraints involved in the optimization concern which can be resolved by implementing the Genetic Algorithm (GA).The concern of optimization, normally can be specified as:

Find $\delta_{\mathrm{k}}, \mathrm{k}=1,2, \ldots, \mathrm{n}$ in order to diminish:

$J=\int_{t_{i}}^{t_{f}}\left(y_{m_{1}}(t)-y_{1}(t)\right)^{2} d t+\int_{t_{i}}^{t_{f}}\left(y_{m_{2}}(t)-\right.$

$\left.\mathrm{y}_{2}(\mathrm{t})\right)^{2} \mathrm{dt}$

subject to the constraints: real parts of the poles of closed loop system should be on left-half of s-plane.

$\left\{\right.$ real $\left.\left[\operatorname{poleC}_{\mathrm{L}}(\mathrm{s})\right]\right\}<0$

where, $y_{m_{1}}(t)$ and $y_{m_{2}}(t)$ are the responses of the models, $\mathrm{M}_{1}(\mathrm{~s})$ and $\mathrm{M}_{2}(\mathrm{~s})$ respectively; where $\mathrm{y}_{1}(\mathrm{t})$ and $\mathrm{y}_{2}(\mathrm{t})$ are the responses of closed loop system with plant and a 2-DOF controller for set point tracking and disturbance rejection respectively; $t_{i}$ and $t_{f}$ are initial time and final time respectively, with $t_{f}-t_{i}$ equal to the operating time of the plant. The stability of the closed loop system is ensured by a constraint in GA in (55)

\section{Numerical Simulation}

The proposed method is illustrated on a coupled-tank that comprises of the two-inputtwo-output process [2], shown in Figure2. In coupled-tank process, the objective is to control the level in both the tanks through the inlet flow of water from both pumps. The inputs 
used in the process are $\mathrm{u}_{1}(\mathrm{t})$ and $\mathrm{u}_{2}(\mathrm{t})$, the input voltages to both the pump. The process outputs includes $\mathrm{h}_{1}(\mathrm{t})$ and $\mathrm{h}_{2}(\mathrm{t})$, water levels in tank1and tank2 respectively.

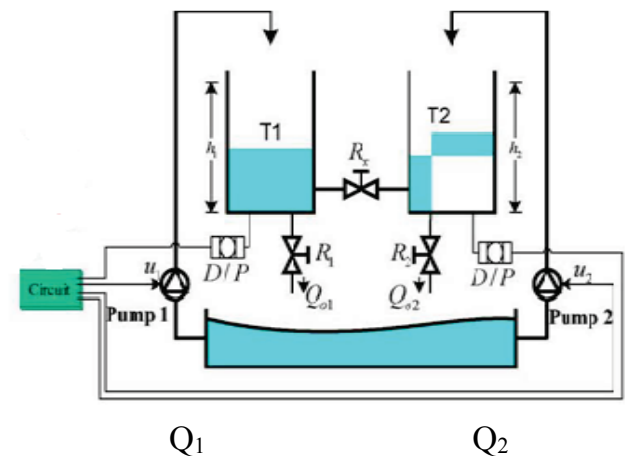

Figure 2. The Coupled-Tank Process [2].

The two-input two-output transfer function matrix $\mathrm{G}(\mathrm{s})$ of coupled-tank process is:

$$
\begin{aligned}
& \mathrm{G}(\mathrm{s})= \\
& {\left[\begin{array}{cc}
\frac{0.04347 \mathrm{~s}+0.0124}{\mathrm{~s}^{2}+0.05461 \mathrm{~s}+0.0006032} & \frac{0.0004638}{\mathrm{~s}^{2}+0.05461 \mathrm{~s}+0.0006032} \\
\frac{0.0005161}{\mathrm{~s}^{2}+0.05461 \mathrm{~s}+0.0006032} & \frac{0.03906 \mathrm{~s}+0.001019}{\mathrm{~s}^{2}+0.05461 \mathrm{~s}+0.0006032}
\end{array}\right]}
\end{aligned}
$$

The model closed loop system $\mathrm{M}_{1}(\mathrm{~s})$ is selected the closed loop transfer function matrix corresponding to the LQG controlled coupledtank process. For a step input disturbance, the model transfer function matrix $\mathrm{M}_{2}(\mathrm{~s})$ corresponding for disturbance rejection is chosen as:

$$
M(s)=\left[\begin{array}{cc}
\frac{10 s}{s^{2}+9 s+10} & 10^{-4} \\
10^{-4} & \frac{s}{s^{2}+3 s+4}
\end{array}\right]
$$

Applying the proposed methodology, a minimized performance index is obtained, $\mathrm{J}=$ 9.3, establishing good matching between the desired and designed responses and a good disturbance rejection too. Weighting matrices of LQG controller, optimal expansion points and Performance Index obtained are given in Table 2. The step response obtained for both set-point tracking and disturbance rejection are given in Figure 3 and Figure 4 respectively. Best fitness value over number of generations is given in Figure 5, shows the smooth convergence of GA. The optimum expansion points are found out by implementing genetic algorithm. The expansion points obtained are $0.3520,-0.8917,-0.0036$ and 0.0272 . Here the performance index, given in (54), comprises of the area between the anticipated response and the accomplished response.

The presentation index, $\mathrm{J}$, is depleted in order to ensure that the accomplished result is way near to the anticipated response.
Table 2. Performance Index, Expansion points and weighting matrices.

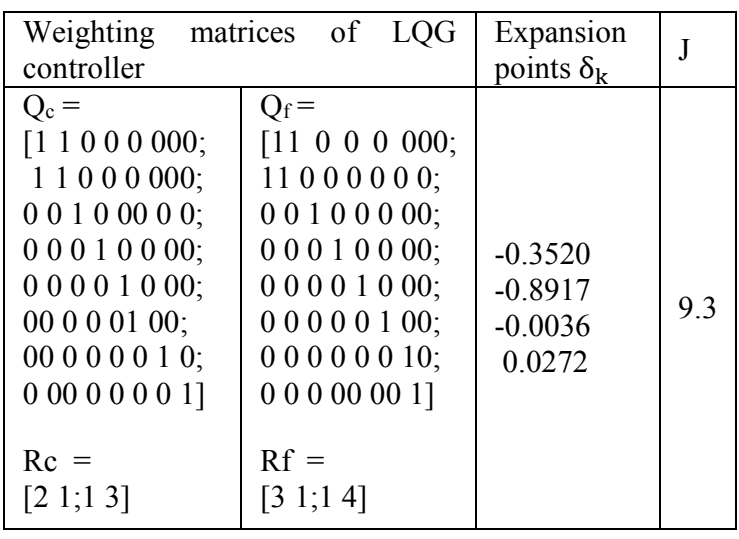

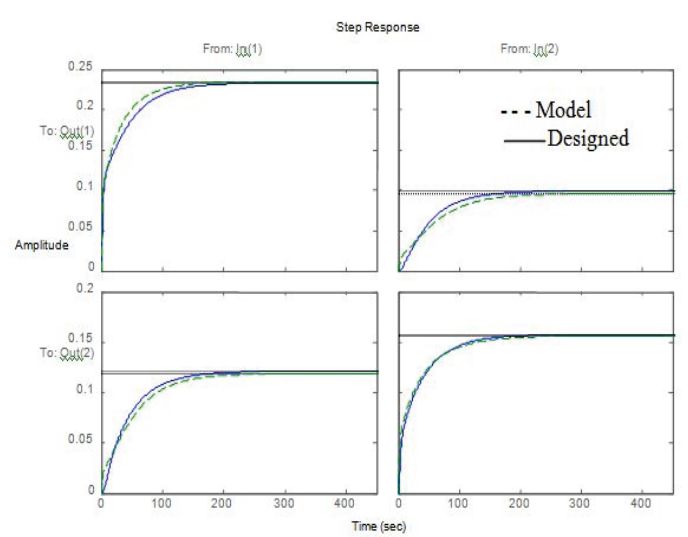

Figure 3. Step responses of the model and closed loop system with 2-DOF controller for set-point tracking

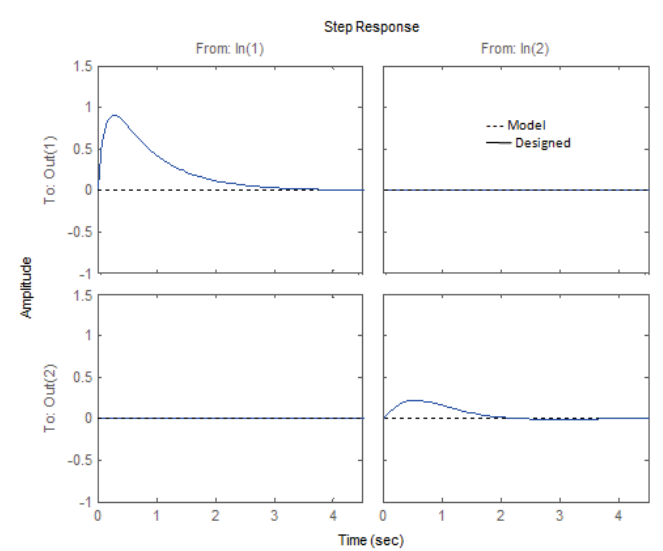

Figure 4. Step responses of the model and closed loop system with 2-DOF controller for disturbance rejection 


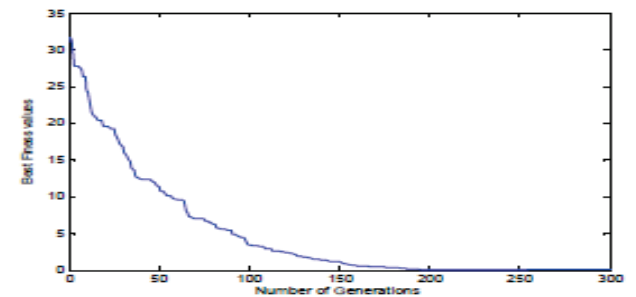

Figure 5. Best fitness value over number of generations plot of GA

These 2-DOF controller parameters can be found out either as Least squares or as hardware flexible solution on user's requirement. Here, both Least squares solution and hardware flexible solution are determined as described in section 3.8.1 and 3.8.2.

The Least squares solution of the 2-DOF controller parameters obtained:

$$
\begin{aligned}
& \mathrm{Q}(\mathrm{s})=\left[\begin{array}{cc}
5.8 \mathrm{~s}+4.8 & 0 \\
0 & 10 \mathrm{~s}+3.2
\end{array}\right] \\
& H(s)=\left[\begin{array}{cc}
1094.9 s+625.6 & 0 \\
0 & 300.5 s+1251.9
\end{array}\right] \\
& \mathrm{K}(\mathrm{s})=\left[\begin{array}{cc}
\frac{1}{\mathrm{~s}+4.2} & 0 \\
0 & \frac{1}{\mathrm{~s}+3.14}
\end{array}\right]
\end{aligned}
$$

The hardware flexible solution of the parameters of the 2-DOF controller:

Let $\mathrm{k}_{1}(\mathrm{~s})=\mathrm{s}+3$ and $\mathrm{k}_{2}(\mathrm{~s})=\mathrm{s}+4$, then $\mathrm{q}_{1}(\mathrm{~s}), \mathrm{q}_{2}(\mathrm{~s})$, $h_{1}(s)$ and $h_{2}(s)$ can be found out from Eq.(19) through Eq.(22).

$$
\begin{aligned}
& Q(s)=\left[\begin{array}{cc}
5.8 s+3.8 & 0 \\
0 & 10 s+4.4
\end{array}\right] \\
& H(s)=\left[\begin{array}{cc}
1094.9 s+11.2 & 0 \\
& 0
\end{array}\right] \\
& K(s)=\left[\begin{array}{cc}
\frac{1}{s+3} & 0 \\
0 & \frac{1}{s+4}
\end{array}\right]
\end{aligned}
$$

\section{Conclusion}

Overall, this paper provides a framework for the less conservative building of a generalized controller belonging to the 2-DOF structure designed for a TITO system, where the resulting output of the closed loop system is found to match the specifications of the desired model while nullifying the effect of disturbance. The concern of finding out the attributes of the controller that belongsto the 2-DOF structure hasbeen obtained from the solution of the array of the linearly non-homogeneous equations. This equation set that comprises of non-homogeneous linear ones are accomplished by using the concept of AGTM/AGMP method in which the closed loop system responds at specific frequency points over the s-plane which synchronizes with the expected design model.

To confront or deal with both the concerns, desired tracking and disturbance rejection, at the same time, it is necessary to acquire a controller with 2-DOF structure. The closed loop system with the proposed controller having 2-DOF specification ensures stabilization of the closed loop system, simultaneously closely synchronizing the expected performance levels by accessing both the signals of output and reference at the same price category as that of the controller that belongs to the 1-DOF specification.

The designed methodology does not impose any limitation neither on the specifications of the model nor the structure or order of the controller transfer matrix. To make it cost effective and to reduce the complexity, the matrices $\mathrm{Q}(\mathrm{s}), \mathrm{H}(\mathrm{s})$ and $\mathrm{K}(\mathrm{s})$ of the 2-DOF controller are taken as diagonal. The anticipated method is easy, affordable and takes less time to compute. Finally, a coupled-tank process is implemented to demonstrate the feasibility and efficiency of the anticipated method along with the simulated results show that excellent control performances of the proposed 2-DOF controller are achieved. In addition, the results obtained in this paper have the potential to be applicable across the interval system, and also the fractional order system and others.

\section{REFERENCES}

1. Antonio Visioli. (2004). A new design for a PID plus feedforward controller, Journal of Process Control, 14, pp.457-463.

2. Arjin Nurnsomrarr, Tianchai Suksri \& Maitree Thumma. (2007). Design of 2DOF PI Controller with Decoupling for Coupled-Tank Process, In Proceedings of the International Conference on Control Automation and Systems, COEX, Seoul, Korea, pp. 17-20.

3. B. C. Kuo. (1995). Automatic Control Systems, Prentice Hall, Englewood Cliffs, NJ.

4. C.A.Desoer, C.L.Gustafson. (1984). Algebraic Theory of Linear Multivariable Feedback Systems. IEEE Transaction on Automatic Control, 29, pp.909-917.

5. Chih-Min Lin, Jiann-Min Wu. (1996). Two-degree-of-freedom Optimal Flight Control System Design. In IEEE Proceedings of the $35^{\text {th }}$ Conference on Decision and Control, Japan, December. 
6. C.M. Liaw. (1992). Design of a TwoDegree-of-Freedom Controller for Motor Drives, IEEE Transaction on Automatic Control, 37(8), 1215-1220.

7. Cristina Şerban, Doina Carp, (2016). Optimization of Container Stowage in a Yard Block Using a Genetic Algorithm, Studies in Informatics and Control, 25(1), pp. 123-130.

8. D.E.Rivera, M.Morari. (1987). Control relevant model reduction problem for SISO using $\mathrm{H}_{\infty}$ and $\mu$ controller synthesis, International Journal of Control, 48(2), pp.505-527.

9. Don Isarakorn, (2012). DC Motor Control using CDM based Two-Degree-ofFreedom Controller for Desired Tracking and Disturbance Rejection Characteristics, In Proceedings of the $12^{\text {th }}$ International Conference on Control Automation and Systems, ICC, pp. $1167-1172$.

10. G.A.Baker, (1975). Essentials of Pade Approximation, Academic Press, New York.

11. I.M.Horowitz. (1963). Synthesis of Feedback Systems, Academic Press.

12. J.G.Truxal, (1955). Automatic feedback control system synthesis, Mc Graw Hill, New York.

13. J.Pal, B.Sarvesh, M.K.Ghosh. (1995). An algebraic method for controller design, Control Theory \& Advanced Technology (Japan), 10(4), pp.2125-2131.

14. J.Pal. (1993). Control system design using approximate model matching, System Science(Poland), 19(3), pp.5-23.

15. Khira Dchich, Abderrahmen Zaafouri \& Abdelkader Chaari. (2015). Combined Riccati-Genetic Algorithms Proposed for Non-Convex Optimization Problem Resolution - A Robust Control Model for PMSM, Studies in Informatics and Control, 24 (3), 317-328.

16. Krishnakumar K., Goldberg D.E. (1992). Control system optimization using Genetic algorithms, Journal of Guidance Control and Dynamics, 15(3), pp.735-740.

17. Miluse Viteckova, Antonin Vitecek. (2008). Two-Degree of freedom controller tuning for integral plus time delay plants, ICIC Express Letters, 2(3), pp.225-229.

18. Mituhiko Araki, Hidefumi Taguchi. (2003). Two-Degree-of-Freedom PID Controllers. International Journal of Control Automation and Systems, 1(4), pp.401-411.
19. Pal.J, (1986). An algorithm method for the simplification of linear dynamic scalar systems, International Journal of Control, 43(1), pp.257-269.

20. Paul Pocatilu, Ion Ivan (2013). A Genetic Algorithm-based System for Automatic Control of Test Data Generation, Studies in Informatics and Control, 22(2), pp.219-226.

21. P.FebinaBeevi, T.K Sunil Kumar \& Jeevamma Jacob. (2016). GA tuned Two Degree of Freedom PID Controller for Time Delay Systems, In Proceedings of International Conference on Innovative Systems, ICIS.

22. P.FebinaBeevi, T.K Sunil Kumar \& Jeevamma Jacob. (2015). Novel Design Method for Two Degree of Freedom Controllers, International Review of Automatic Control, 8(4), pp.281-288.

23. P.FebinaBeevi, T.K Sunil Kumar \& Jeevamma Jacob. (2016). Two Degree of Freedom Controller Design By AGTM $\backslash$ AGMP Matching Method for Time Delay Systems, Procedia Technology, Elsevier, 25, pp.20-27.

24. Peter Dorato, Chaouki Abdallah \& Vito Cerone, (1995). Linear-Quadratic Control: An Introduction, Prentice Hall, New Jersey.

25. S.Banerjee, T.K. Sunil Kumar, J.Pal, D. Prasad. (2006). A novel method for controller design for simultaneous stabilization and performance improvement of an electromagnetic levitation system, Asian Journal of Control, 8(1), pp.50-55.

26. Weidong Zhang, Wei Wang, Xing He, Xioming Xu. (2003). Analytical Design of New Two-Degree-of-Freedom Controller for Integrating processes. In Proceedings of the $42^{\text {nd }}$ IEEE Conference on Decision and Control, pp. $2496-3619$.

27. William A. Wolovich. (1994). Automatic Control System: Basic analysis \& design, Saunders College Publishing, Harcount Brace College Publishers, New York.

28. Zhang Wei, Sun Bo, Zhang Xi \& Zhang Weidong. (2013). Two-degree-of-freedom Controller Design for MIMO Systems with Multiple Time Delays Based on Inversing Decoupling, In Proceedings of the $32^{\text {nd }}$ Chinese Control Conference, Xi' an, China, pp. 26-28. 